\title{
Methodological Error of Angle Measurement by Artillery Sound Ranging System
}

\author{
Roman Kochan \\ Dept. of Computer Science and Automatic \\ University of Bielsko-Biala, Poland, \\ Dept. of Specialized Computer Systems \\ Lviv Polytechnic National University \\ Lviv, Ukraine \\ e-mail: kochan.roman@gmail.com
}

\author{
Bogdan Trembach \\ Dept. of Specialized Computer Systems \\ Lviv Polytechnic National University \\ Lviv, Ukraine \\ e-mail: trembach.bogdan@gmail.com
}

\author{
Orest Kochan \\ Dept. of Information Measurement Technologies \\ Lviv Polytechnic National University \\ Lviv, Ukraine \\ e-mail: orestvk@gmail.com
}

\begin{abstract}
The methodology of artillery sound ranging devices, adopted by the Armed Forces of Ukraine, is analyzed. The mathematical model, which describes the dependence of methodological error of measuring the angle of the direction to target measured by sound ranging, is developed. Analyzes of this model provides the dependence of methodological error from distance to target and orientation of acoustic base.
\end{abstract}

Index Terms-Artillery Sound Ranging; Methodology Error; Linearization

\section{INTRODUCTION}

Artillery sound ranging is method of intelligent support of artillery in Armed Forces of Ukraine (AFU). It is oriented on measurement the coordinates of targets based on sound of their shooting. The artillery units of enemy are such targets as well as the places of actual hitting of own artillery [1]. The sound metric stations AZK-7 [2] and AZK-5 [3] provides artillery sound ranging adopted by the AFU. These stations are based on analogue sound signal processing and mostly have exhausted their technical resource till now. As the result the state of technical readiness of these stations does not provides effective performing the tasks of artillery intelligence during the active stage of the war in the east of Ukraine in 2014-2015 $[4,5]$. Till now these stations are restored [6]. However their parameters caused by semi-automatic data exchanging and processing does not corresponds to requirements of modern war. Also the method of sound ranging was implemented for anti-sniper defense [7]. It significantly increases the requirements to coverage of artillery sound ranging system as well as amount of users of information produced by this equipment and in the same time increase limitation to time delay of data transferring and processing.
Sound ranging systems are implemented in armored forces of different countries $[8,9,10]$ as well as in police department $[11,12]$. Taking in to consideration that these systems where implemented in last decade the method of sound ranging is actual [13].

The developed in Ukraine sound metric station of new generation "Polozhenie-2" [14, 15] mostly meet these requirements. This station is approved by AFU from 2013 but the amount of its production does not correspond to the requirements. It was developed the distributed system of sound artillery ranging [16] based on cellular communication channels. This system consists from the set of autonomous portative sound receivers, which are connected into the network. Server of the system also is included into this network and provides data collection, processing and presenting to users according their access rights. This system provides easy increasing the number of measurement channels and national or international (in the roaming mode) coverage.

The goal of this work is analysis of methodology error of angle measurement in artillery sound ranging systems.

\section{APPROACH OF ARTILLERY SOUND RANGING}

The concept of sound ranging systems is based on implantation effect of stereophonic sound [17] for measurement the angle to the sound source from the center of acoustic base (AB). The coordinates of sound source is determined as the palace of crossing by the rays carried out from several centers of $\mathrm{AB}$ with appropriate angles. The suchlike method is presented in $[18,19]$. Angle measurement according methodology presented in $[1,20]$ uses assumption that front of acoustic wave dissemination is flat in the projection of $\mathrm{AB}$. This assumption is false especially when the 
distance to sound source is commensurate to the distance between sound receivers. This assumption brings some methodology error of angle measurement and this is actual for distributive system of artillery sound ranging presented in [10].

$\mathrm{AB}$ consists of two sound receivers placed with some distance between each other. These receivers monitor own acoustic environment. The geometric model of $\mathrm{AB}$ is presented on Fig. 1 [1]. Points $\mathrm{A}$ and $\mathrm{B}$ are the positions of sound receivers. The length of straight line segment $A B$ is the length of $\mathrm{AB}-\mathrm{L}$. Led the point $\mathrm{D}$ is position of the target. Then there is sound wave distributed in all directions from this point. The front of this wave is growing circle with the center in point $D$. The speed of this sound wave distribution is sound speed in the air. Than we can write the following relations

$$
\left\{\begin{array}{l}
D B=V \times t_{D B} \\
D A=V \times t_{D A}
\end{array},\right.
$$

where $V$ - speed of the sound distribution in the air, $t_{D A}$ and $t_{D B}$ - times of sound waves passing thru section DA and DB correspondently.

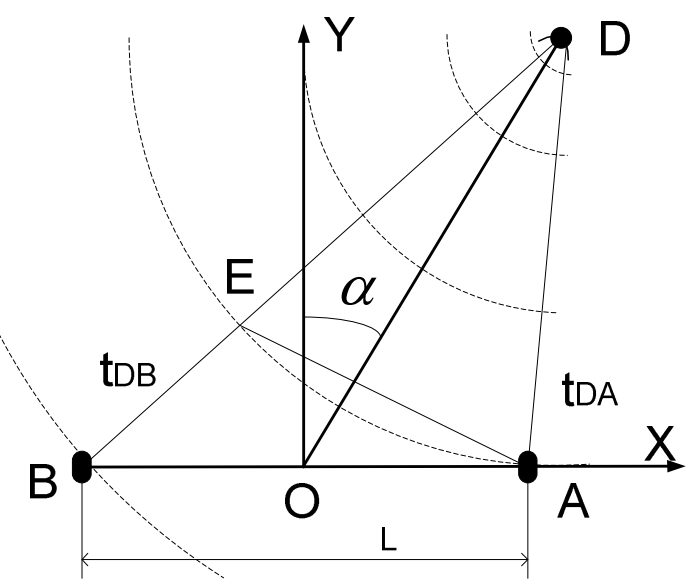

Fig. 1. Geometric model of acoustic base

If we put point $E$ on segment $D B$ such that $D E=D A$, it mean that front of sound wave get to points $E$ and $A$ in the same time moment. Therefore the difference of time $\Delta_{t}$ of passage of the front of the sound wave of segments $D B$ and $D A$ is $\Delta_{t}=t_{D B}-t_{D A}=t_{E B}\left(t_{E B}\right.$ - time of passage of the front of the sound wave of segment $E B$ ) and it is possible to measure by starting of timer in the moment of registration of the sound wave in the point $A$ and stopping in the moment of its registration in the point $B$. Than the point $D$ belongs to the hyperbola, as it is presented in fig. 2 [21]. The sound receivers are foci of this hyperbola and the difference of the distances from any point of hyperbola to these foci - length of segment $B E$. If we construct such Cartesian coordinate system that $\mathrm{X}$-axis pass thru sound receivers. The origin of this coordinate system is midpoint of hyperbola (center of segment $A B)$. This hyperbola function is following

$$
\frac{x^{2}}{a^{2}}-\frac{y^{2}}{b^{2}}=1
$$

where $x$ and $y$ - abscissa and ordinate of points of hyperbola, $a$ and $b$ - transverse and conjugate semiaxes of hyperbola correspondently.

The following correlation is fulfilled [21]

$$
a^{2}+b^{2}=c^{2}
$$

where $2 c$-distance between the foci of hyperbola.

For the presented on Fig. 1 geometric model of $\mathrm{AB}$ the following correlations are fulfilled

$$
\left\{\begin{array}{l}
2 a=V \times \Delta_{t} \\
2 c=L
\end{array}\right.
$$

where $L$ - length of AB.

Substituting the equation (3) and (4) into (2) we will get after simplification

$$
\frac{x^{2}}{\left(V \times \Delta_{t}\right)^{2}}-\frac{y^{2}}{L^{2}-\left(V \times \Delta_{t}\right)^{2}}=4 .
$$

Having brought to the traditional representation of the function, we obtain

$$
y= \pm \sqrt{\left(\frac{x^{2}}{\left(V \times \Delta_{t}\right)^{2}}-4\right) \times\left(L^{2}-\left(V \times \Delta_{t}\right)^{2}\right)}
$$



Fig. 2. Hyperboles that have the location of the target

The real angle to the sound source $\alpha$ - angle between yaxis and segment OD we can compute as following 


$$
\begin{aligned}
& \operatorname{ctg}(\alpha)=\frac{y}{x}= \\
& = \pm \frac{1}{x} \sqrt{\left(\frac{x^{2}}{\left(V \times \Delta_{t}\right)^{2}}-4\right) \times\left(L^{2}-\left(V \times \Delta_{t}\right)^{2}\right)}= \\
& = \pm \sqrt{\left(\frac{1}{\left(V \times \Delta_{t}\right)^{2}}-\frac{4}{x^{2}}\right) \times\left(L^{2}-\left(V \times \Delta_{t}\right)^{2}\right)}
\end{aligned}
$$

\section{METHODOLOGY ERROR OF MEASUREMENT THE ANGLE TO THE SOUND SOURCE}

The methodology of angle to the sound source computing, which is presented in $[1,20]$, provides approximation of hyperbola by its asymptotes and using the following equation

$$
\begin{aligned}
& \operatorname{ctg}(\beta)=\frac{b}{a}= \pm \sqrt{\frac{\left(L^{2}-\left(V \times \Delta_{t}\right)^{2}\right)}{\left(V \times \Delta_{t}\right)^{2}}}= \\
& = \pm \sqrt{\left(\frac{L}{V \times \Delta_{t}}\right)^{2}-1}
\end{aligned}
$$

Than the methodology error $\Delta_{M}$ of angle to the sound source measurement is

$$
\Delta_{M}=\alpha-\beta
$$

We can compute this error using elementary trigonometric transformations

$$
\operatorname{ctg}\left(\Delta_{M}\right)=\frac{\operatorname{ctg}(\alpha) \times \operatorname{ctg}(\beta)+1}{\operatorname{ctg}(\beta)-\operatorname{ctg}(\alpha)}
$$

Substituting the equation (7) and (8) into (10) we will get after simplification

$$
\left\{\begin{array}{l}
\left(V \times \Delta_{t}\right)^{2}=\frac{L^{2}}{\operatorname{ctg}^{2}(\beta)+1} \\
\operatorname{ctg}\left(\Delta_{M}\right)=\frac{1+\operatorname{ctg}(\beta) \times \sqrt{\left(\operatorname{ctg}^{2}(\beta)+1-\frac{4 \times L^{2}}{x^{2}}\right) \times\left(1-\frac{1}{\operatorname{ctg}^{2}(\beta)+1}\right)}}{\operatorname{ctg}(\beta)-\sqrt{\left(\operatorname{ctg}^{2}(\beta)+1-\frac{4 \times L^{2}}{x^{2}}\right) \times\left(1-\frac{1}{\operatorname{ctg}^{2}(\beta)+1}\right)}}
\end{array}\right.
$$

The graph of the dependence of error $\Delta_{M}$ from $\beta$ and $\frac{x}{L}$ for $\beta \in\left[0^{0}, 90^{\circ}\right]$ and $\frac{x}{L} \in[2,5]$ is presented on fig. 3 . The domain of this function is $\beta \in\left[-180^{\circ}, 180^{\circ}\right], \frac{x}{L} \in\left[\frac{V \times \Delta_{t}}{L}, \infty\right)$. Further we will consider only the quadrant I of hyperbola graph. It is because quadrant IV ( $\Delta_{M}$ for $\beta \in\left[-90^{\circ}, 0^{\circ}\right]$ ) is equivalent to quadrant I with opposite sign and quadrants II and III ( $\left.\beta \in\left[90^{\circ}, 270^{\circ}\right]\right)$ repeats quadrants $\mathrm{I}$ and IV $\left(\beta \in\left[-90^{\circ}, 90^{\circ}\right]\right)$ correspondently. The maximum value of methodology error is achieved for minimal value of relation $x / L$, and increasing of relation $x / L$ leads to monotonic decreasing of error and its value asymptotically directs to zero. The maximal value of methodology error for fixed relation $x / L$ is achieved for $\beta=62^{\circ}$ and it is $14^{\circ}$. This value 14 times exceeds instrumental error of station AZK-5 and 17.5 times exceeds instrumental error of station AZK-7.

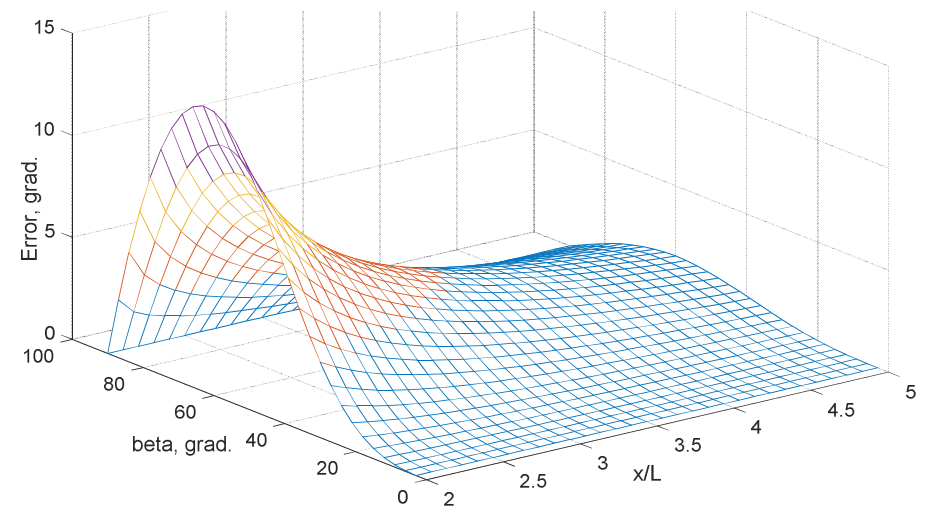

Fig. 3. Graph of methodology error $\Delta_{M}$ dependence from

$$
\beta \text { and } \frac{x}{L}
$$

\section{CONCLUSIONS}

The analysis of implementation methodology of sound metric stations AZK-5 and AZK-7 show that this methodology provides approximation of second order curve - hyperbola, that have the location of the target, by the asymptotic rays of this hyperbola. This approximation provides simplification of mathematics and geodesic computing but brings methodology error of angle to target measurement. Analysis of this methodology error shows that it can significantly exceed instrumental error of sound metric stations if the distance to target slightly exceeds the length of acoustic base. The correction of this methodology error is not provided by active methodology of sound metric stations implementation. This methodology error is systematic therefore target coordinates measurement and counter-battery fire correction by the same sound metric stations significantly decrease its influence. However this error complicates the compatibility of measurement results as well with other sound metric stations as with other types of intelligence. The level of this methodology error is decreasing if distance to target increasing. Therefore it is logical for implementation, more accurate, methods of angle to target computing. It will increase the computing complexity of the system. This problem was actual in the time of development of mentioned sound metric stations but modern computers and communication technologies provides 
automation all measurement and computing functions [22], which are required in sound ranging implementation, including: topographic binding, acoustic environment monitoring, communication between components of the system [23] as well as data aggregation using any algorithm of data processing in real time mode [24] and reprogramming on operating program using active communication interface during operation [25]. These publications are not connected to sound ranging but they consider appropriate aspects of distributive DAQ systems development.

\section{REFERENCES}

[1] Kryvosheev A.M., Petrenko V.M., Pryhodko A.I. Basics of Artillery Intelligence: Tutorial. Publishing house of Sumy State Technical University, 2014. - 393 p. (in Ukrainian)

[2] http://home.farlep.net/ kpmo/azk_r.htm

[3] http://uk.wikipedia.org/wiki/A3K-5

[4] Ustymenko O.V. Perspectives on the Development the Scouting and Shock System Based on Multiple Launch Rocket System. Proceedings of Conference "Perspectives of Development of Rocket and Artillery Troops for Ground Forces". Lviv, 5 - 6 Nov. 2014, pp. 203 - 206. (in Ukrainian)

[5] Petluk O.I. Petluk I.V. Features of the Using the Artillery Intelligence Units During the Conduct of Hostilities During ATO. Proceedings of Conference "Perspectives of Development of Arming and Military Equipment for Ground Forces". Lviv, 14 - 15 May 2015, pp. 114 - 115. (in Ukrainian)

[6] https://www.ukrinform.ua/rubric-society/2337207-ukraina-majzepovnistu-vidnovila-radiotehnicnu-rozvidku-porosenko.html

[7] Fures O.O., Potockyj O.O., Rij V.B. Development the Counter-Sniper Tactic in Units of Army Forces of Ukraine. Abstracts of International Conference "Perspectives of Development of Arming and Military Equipment for Ground Forces”. Lviv, 11 - 12 May 2017, p. 114.

[8] http://metravib.acoemgroup.com/defence/catalog/METRAVIB-PILAR$\underline{\mathrm{V}}$

[9] https://topwar.ru/37817-akusticheskie-sistemy-opredeleniyavystrela.html

[10] http://www.mil.gov.ua/ministry/zmi-pro-nas/2014/09/22/pochutita\%E2\%80\%A6-znishhiti

[11] https://www.ncjrs.gov/pdffiles1/nij/179274.pdf

[12] http://360tech.ru/2016/05/22/akusticheskij-lokator-shotspotter/

[13] http://peleng360.com/
[14] "Polozheniye 2" (1AR1) Sound Ranging System // Ukroboronprom catalogue 2016-2017. p. 173.

[15] R\&D Project Position RB3 [NDR Polozhenie - RB3], Sumy NC BZ RViA, Sumy State University, 2008, 115 p.

[16] Kochan R.V., Trembach B.R. Approach of distributive automatic sound ranging system based on cellular communication. Modern information technologies in the sphere of security and defense. Kyiv, 2016, № $1(25), \quad$ pp. $59 \quad-\quad 63 . \quad$ (http://nuou.org.ua/prouniversytet/dokumenty/finish/16-zhurnal-suchasni-informatsiinitekhnolohii-u-sferi-bezpeky-ta-oborony/1546-naukovyizhurnalsuchasni-informatsiini-tekhnolohii-u-sferi-bezpeky-ta-oborony1-25-2016/0.html)

[17] http://en.wikipedia.org/wiki/Artillery_sound_ranging

[18] Hanshan Li, Zhiyong Lei. Projectile Two-dimensional Coordinate Measurement Method Based on Optical Fiber Coding Fire and its Coordinate Distribution Probability. MEASUREMENT SCIENCE REVIEW, Volume 13, No. 1, 2013, pp. $34-38$.

[19] Êmec V., and Jan Rogowski. Mathematical-Numerical Modelling of Ultrasonic Scattering Data from a Closed Obstacles and Inverse Analysis. Academic Publishing House Exit, 2013.

[20] Talanov A.V. (1948), Sound intelligence of artillery. [Zvukovaja razvedka artilerii], Publishing house of ministry of military forces of USSR, Moskow, 404 p.

[21] Sherman K. Stein. Calculus and analytic geometry. McGraw-Hill Companies, 1987.

[22] Stepanenko A., Lee K., Kochan R., Kochan V., Sachenko A. Development of a minimal IEEE 1451.1 model for microcontroller implementation. Proc. of the Sensors Applications Symposium (SAS'2006), 2006. pp. 88-93.

[23] V. Hrusha, O. Osolinskiy, P. Daponte, D. Grimaldi, R. Kochan, A. Sachenko, I. Turchenko. Distributed Web-based measurement system. Proc. of IEEE Workshop on Intelligent Data Acquisition and Advanced Computing Systems: Technology and Applications (IDAACS 2005) 5-7 September 2005, Sofia, Bulgaria. pp. 355-358.

[24] N. Vasylkiv, O. Kochan, R. Kochan, M. Chyrka. The control system of the profile of temperature field. Proc. of IEEE Workshop on Intelligent Data Acquisition and Advanced Computing Systems: Technology and Applications (IDAACS 2009). 21 - 23 September 2009, Rende, Italy, pp. 201-206.

[25] V. Kochan, K. Lee, R. Kochan, A. Sachenko. Approach to improvement the network capable application processor compatible with IEEE 1451 standard. Proc. of Second IEEE International Workshop on Intelligent Data Acquisition and Advanced Computing Systems: Technology and Applications (IDAACS 2003). 8 - 10 September 2003, Lviv, Ukraine, pp. 437-441. 